${ }^{1}$ Szabadi, E., and Bradshaw, C. M., Nature New Biology, 239, 152 (1972).

2 Stone, T. W., Nature, 234, 145 (1971).

3 Karlsberg, P., Elliott, H. W., and Adams, J. E., Neurology, 13, $772(1963)$

4 Essen, C. von, J. Pharm. Pharmac., 24, 668 (1972).

5 Roberts, M. H. T., and Straughan, D. W., J. Physiol., 193, 269 (1967).

6 Boakes, R. J., Bradley, P. B., Briggs, I., and Dray, A., Brain Res., 15, 629 (1969).

7 Vlahov, V., and Jordanov, B., Abstr. XXV Int. Congr. Physiol. Sci., Munich., 9, 589 (1971).

8 Yordanov, B. I., and Vlahov, V., in Brain and Blood Flow (edit. by Ross Russell, R. W.) (Pitman, London, 1970).

9 Deshmukh, V. D., and Harper, A. M., in Brain and Blood Flow (edit. by Ross Russell, R. W.) (Pitman, London, 1970).

\section{Noradrenaline Artefacts: a Reply}

WE have suggested ${ }^{1}$ that the excitatory responses of single neurones to 5-hydroxytryptamine (5-HT), isoprenaline, and mescaline could hardly be explained on the basis of an assumed vasoconstrictor action of the monoamines on small cerebral blood vessels ${ }^{2}$.

Whilst agreeing with Stone ${ }^{3}$ that 5 -HT has a complex action on cerebral blood vessels, we wish to point out that the reduction in cerebral blood flow brought about by the intra-carotid injection of 5-HT seems to be due to a constriction of the internal carotid artery alone, and not to a general constriction of cerebral arteries ${ }^{4}$. Thus, it would be premature to suppose that microelectrophoretically applied 5-HT would constrict blood vessels of the dimensions relevant to Stone's hypothesis. Further, the observation that $\beta$-adrenoceptor antagonists reduce cerebral blood volume ${ }^{5}$ would seem to argue against Stone's proposal that the action of isoprenaline on single neurones can be explained in terms of a vasoconstrictor action.

The similarity between the time-courses of neuronal responses to noradrenaline, 5-HT, isoprenaline and mescaline could be explained by the similarity between the mobilities (reflected in the transport number and the diffusion coefficient) of the molecules of these monoamines. There is evidence ${ }^{6,7}$ that the kinetics of neuronal response are largely determined by physical processes (kinetics of drug release from the micropipette, diffusional spread of the drug in the tissue). These processes in turn are largely determined by the mobility of the drug molecules. As these physical factors are equally relevant in determining the kinetics of vascular responses to microelectrophoretically applied drugs, it should not be surprising that vascular and neuronal responses to the same drug have similar time courses.

\section{E. SzaBadi \\ C. M. BRADSHAW}

Department of Psychiatry,

University of Edinburgh,

Morningside Park,

Edinburgh EH10 $5 H F$

Received January 26, 1973.

${ }^{1}$ Szabadi, E., and Bradshaw, C. M., Nature New Biology, 239, 152 (1972).

2 Stone, T. W., Nature, 234, 145 (1971).

3 Stone, T. W., Nature New Biology, 242, 244 (1973)

4 Deshmukh, V. D., and Harper, A. M., in Brain and Blood Flow (edit. by Ross Russell, R. W.), 136 (Pitman, London, 1970).

5 Yordanov, B. I., and Vlahov, V., in Brain and Blood Flow (edit. by Ross Russell, R. W.), 233 (Pitman, London, 1970).

6 Bradshaw, C. M., Roberts, M. H. T., and Szabadi, E., Brit. J. Pharmacol., 47, 653P (1973).

7 Bradshaw, C. M., Szabadi, E., and Roberts, M. H. T., J. Pharm. Pharmacol. (in the press)

\section{Noradrenaline Excitations: Neuronal, not Vascular}

STONE ${ }^{1}$ suggested that noradrenaline (NA) excitations of central nervous system (CNS) neurones may be indirect effects due to localized vascular changes causing hypoxia, because (1) he found that iontophoretic application of noradrenaline to small mesenteric vessels caused vasoconstriction with a latency and time-course comparable to the excitant effects of noradrenaline on CNS neurones; (2) hypoxia was shown by Lorente de $\mathrm{No}^{2}$ to cause depolarization in nerve fibres; (3) halothane is known to enhance the response of small blood vessels to catecholamines ${ }^{3}$; (4) Johnson et al. ${ }^{4,5}$ reported that noradrenaline excitation of cortical neurones occurred predominantly in cats under halothane anaesthesia and less frequently in those anaesthetized with barbiturate; and (5) Phillis and York ${ }^{6}$ obtained fewer noradrenaline excitations using methoxyflurane, which diminishes peripheral blood vessel sensitivity to catecholamines.

This hypothesis is not compatible with other findings described by Johnson et al. ${ }^{4,5}$. First, noradrenaline excitations were almost as common in unanaesthetized preparations $(47.8 \%)$ as in halothane-anaesthetized preparations $(56.8 \%)$. Even if this difference is regarded as significant, only a very small proportion of noradrenaline excitations can thus be ascribed to halothane sensitization. Second, the beta-adrenoceptor agonist isoprenaline, which is not a vasoconstrictor, excited $47 \%$ of cortical neurones tested; 35 of 36 neurones tested with noradrenaline and isoprenaline showed the same response to both. Also, noradrenaline excitations were blocked both by alpha and beta antagonists, and more consistently by beta antagonists. Third, many cells responded oppositely to noradrenaline and to 5-hydroxytryptamine (5-HT), which also has vasoconstrictor properties ${ }^{7}$, though each of these drugs excited about $50 \%$ of neurones tested. Fourth, hypoxia causes a reduction in spike amplitude, but no such reduction in spike height was observed with excitations due to noradrenaline, isoprenaline or 5-hydroxytryptamine. Fifth, halothane appears to increase cortical blood flow ${ }^{8-10}$, therefore the unmasking of a noradrenaline excitation by halothane can hardly be ascribed to neuronal hypoxia.

In view of Stone's data, we re-examined in detail the latencies of noradrenaline excitations, and found that these latencies are not "strictly comparable" to those of peripheral vasoconstrictor effects; of 113 excitations, 71 (63\%) occurred with latencies of $30 \mathrm{~s}$ or less. Latencies of this order have been reported for acetylcholine excitations in cortex ${ }^{11}$, and are less than $50 \%$ of the vasoconstriction latency indicated in Stone's figure. Latencies greater than $30 \mathrm{~s}$ were encountered only with cells whose basal firing rate $\left(\mathrm{y}_{0}\right)$ had been less than $10 \mathrm{~s}^{-1}$. In fact, a very strong semi-logarithmic, inverse relation held between basal firing rate $\left(1 \leq \mathrm{y}_{0} \leq 85\right.$ spikes $\left.\mathrm{s}^{-1}\right)$ and latency $(1 \leq \mathrm{L} \leftrightharpoons 60 \mathrm{~s})$ for both noradrenaline $(r=-0.992)$ and 5-hydroxytryptamine $(r=-0.980)$. This was not simply a difference amongst cells as shown by the responses of fifteen cells to two iontophoretic applications of noradrenaline (Table 1). In fourteen of these cases, basal firing rate was

Table 1 Relation Between Basal (Pre-Drug) Firing Rate and Latency of Noradrenaline Excitation *

$\begin{array}{cccc}\begin{array}{c}\text { Excitation } \\ \text { latency }\end{array} & \mathrm{y}_{0_{1}}>\mathrm{y}_{\mathrm{O}_{2}} & \begin{array}{r}\text { Firing rates } \\ \mathbf{y}_{0_{1}}=\mathrm{y}_{0_{2}}\end{array} & \mathrm{y}_{\mathrm{o}_{1}}<\mathrm{y}_{\mathrm{o}_{2}} \\ \mathbf{L}_{1}<\mathrm{L}_{2} & 4 & 0 & 0 \\ \mathbf{L}_{1}=\mathbf{L}_{2} & 0 & 1 & 1 \\ \mathbf{L}_{1}>\mathrm{L}_{2} & 0 & 0 & 9\end{array}$

* 15 cells which were iontophoresed twice. $\mathrm{y}_{0_{1}}, \mathrm{y}_{0_{2}}$ : basal firing rate before first and second drug application, respectively. $\mathrm{L}_{1}, \mathrm{~L}_{2}$ : excitation latency on first and second drug application, respectively. The relation is highly significant $\left(\chi_{1}^{2}=15.21, P<0.00025\right)$. 